\title{
Patterns of service use among people with learning disabilities discharged from long-stay hospital care in Northern Ireland
}

\author{
Sinéad McGilloway \& Michael Donnelly
}

Ir J Psych Med 1999; 16(3): 109-113

\begin{abstract}
Objectives: Continuing deinstitutionalisation has led to growing concern about the availability and accessibility of services for people with learning disabilities transferring to community living. This study was undertaken in order to assess the configuration of services in terms of availability and uptake for people with learning disabilities who have left long-stay hospital care and to identify gaps or barriers to service provision within the unique integrated health and social services structure in Northern Ireland.

Method: The 'keyworkers' of 195 people - most of whom were aged 40-59 years with a diagnosis of moderate intellectual impairment - were interviewed by a researcher one year after discharge using the Service Interview.

Results: While a wide range of generic and specialist services was available, 'packages' of care consisted largely of public sector services (eg. GPs, chiropodists and social workers) and relied, to some extent, on the type of community accommodation. Although services appeared well co-ordinated in terms of care reviews and keyworker arrangements, $40 \%$ of people required more one-to-one support particularly in areas related to integration. However, services were perceived by care staff to be satisfactory

Conclusions: The development of community care has been slower in Northern Ireland than elsewhere and a large proportion of resources remain tied up in hospital care. However, existing community-based services appear to be addressing individual needs. Some former patients, though, may have been subject to transinstitutionalisation in the sense that their choice of community accommodation was restricted mainly to large private sector homes and work and daytime opportunities were insufficient to facilitate integration. Service planners and providers need to give further consideration to the likely effects of different forms of rehabilitation, reprovision and resettlement and to be aware that the pattern of service provision is likely to be different for the more dependent cohorts of people who leave hospital in the future.
\end{abstract}

Keywords: Learning disability; Community care; Longstay hospital.

\section{Introduction}

Service availability and accessibility have become issues of growing concern with the continuing implementation of

*Sinéad McGilloway, PhD, Research Fellow,

Michael Donnelly, PhD, Reader, Health and Social Care

Research Unit, Queen's University Belfast, Mulhouse Building,

Institute of Clinical Science, Grosvenor Road, Belfast BT12 6BJ,

Northern Ireland.

*Correspondence

SUBMITTED: JULY 30, 1998. ACCEPTED: JUNE 25, 1999. the discharge policy, but only a small number of studies have examined service provision for former hospital residents with learning disabilities.

The relocation from long-stay hospital care to the community may lead to transitory behavioural problems and other forms of transfer trauma in people with learning disabilities. ${ }^{2,3}$ It is important, therefore, that comprehensive and well co-ordinated services are available following discharge. Northern Ireland has an integrated health and social services structure administered by the Department of Health and Social Services (DHSS) via four HSS boards and 20 HSS trusts. In its 1987-1992 regional strategy, the DHSS set specific targets of a $20 \%$ reduction in the numbers of people in long-stay learning disability hospitals. 'Bridging' funds totalling approximately $£ 34$ million over six years were allocated to the four health and social services boards to assist in developing appropriate forms of community care (for both psychiatric and learning disability populations).

Although this goal was successfully achieved, little was known about former patients or their use of services. In 1991 , the DHSS proposed a further reduction of $30 \%$ in the long-stay hospital population by 1997 , and more recently advocated the development of "a comprehensive range of supportive services for people with a learning disability and their carers, the aim being to reduce to zero by 2002 the number of long-stay patients in hospital". ${ }^{6}$

However, the rate of hospital retraction in Northern Ireland has for some time lagged considerably behind the rest of the UK ( $44 \%$ of hospital places open in England in 1980 were still open in 1992 compared to $70 \%$ in Northern Ireland). Consequently, the three learning disability hospitals in Northern Ireland are providing accommodation and care for a total of 533 long-stay inpatients. It is also important to note that, according to a review of services for people with learning disability in Northern Ireland, approximately $90 \%(7,455 / 8,258)$ (in 1993) live in the community.

The aims of this study were to:

- outline the background characteristics and community destinations of people with learning disabilities one year after discharge

- describe patterns of service use including the staffperceived availability, accessibility and appropriateness of services.

The study was undertaken as part of a larger evaluation of community care for 497 people discharged during 1987 1992 from the three learning disability hospitals in Northern Ireland. This paper focuses on those discharged between 1990 and 1992 (see Donnelly et al for details of the study background and former patients).

\section{Method}

The Service Interview $(\mathrm{SI})^{8}$ was used to collect informa- 
Table 1: Receipt of services by type of community accommodation

\begin{tabular}{|c|c|c|c|c|c|c|c|c|c|c|c|c|}
\hline \multicolumn{13}{|c|}{ Percentage of people receiving services* } \\
\hline Type of accommodation & GP & CHIR & DENT & SW & CONS & DPTIC & OTHER & CMHN & OT & PHYS & PSYC & DN \\
\hline \multicolumn{13}{|l|}{ Private } \\
\hline Nursing home $^{\star \star}(n=22)$ & 67 & 56 & 55 & 46 & 21 & 22 & 13 & 3 & 12 & 7 & 2 & 2 \\
\hline Residential home $(n=21)$ & 78 & 61 & 61 & 22 & 17 & - & 22 & 22 & - & - & - & 6 \\
\hline \multicolumn{13}{|l|}{ Public } \\
\hline $\begin{array}{l}\text { Hostel/Residential home } \\
(n=28)\end{array}$ & 87 & 71 & 77 & 58 & 19 & 23 & 29 & 10 & 10 & 6 & 3 & 3 \\
\hline \multicolumn{13}{|l|}{ Voluntary } \\
\hline $\begin{array}{l}\text { Hostel/Residential home } \\
(n=22)\end{array}$ & 86 & 62 & 62 & 57 & 52 & 38 & 10 & 38 & - & 5 & - & - \\
\hline $\begin{array}{l}\text { Living with the family } \\
(n=4)\end{array}$ & 50 & - & 100 & 50 & - & - & - & 50 & - & 50 & - & - \\
\hline Total $(n=197)$ & 73 & 63 & 60 & 47 & 23 & 22 & B & 12 & $\mathbf{g}$ & 5 & 2 & 2 \\
\hline
\end{tabular}

tion from care staff about the services received by each former hospital resident during the period between six and 12 months after discharge. This six-month period was chosen, firstly, because it reflected a longer term picture (ie. service provision during the first six months after discharge might not be typical) and, secondly, because services received during this time could be more easily recalled at the one-year follow-up. The SI is completed by a researcher in conjunction with a 'keyworker' or other care professional (eg. a staff nurse). Information was collected for all those still living in the community at the one year follow-up and for one person who was re-admitted to hospital just before the one-year follow-up was due ( $\mathbf{n}=$ 197).

The data are based on:

- contact with approximately 25 services

- frequency and duration of service use

- whether or not the service was provided at home or elsewhere.

Interviewees were also asked to rate broadly (on a scale from one (high) to three (low)) their level of satisfaction with the availability/accessibility of services (eg. 'usually sufficient') and their quality/appropriateness (eg. usually 'helpful/appropriate'). Unmet need, gaps in service provision (eg. poor communication between staff) and other relevant care staff inputs (eg. care review meetings) were also recorded in order to assess the extent to which services were tailored to individual need.

\section{Results}

Background characteristics and community destinations

A total of 214 people left hospital between April 1990 and June 1992. The majority at each hospital were males aged between 40 and 59 years who had spent over 20 years in hospital and who had a moderate degree of intellectual impairment (which for the purposes of this study refers to people with IQ scores of between 20 and 49). Characteristics were summarised along several dimensions by year of discharge; for example, $55 \%$ of the 131 people who left hospital in 1991 were male; $47 \%$ (61/131) were aged $40-59$ years while $25 \%(33 / 131)$ were aged $60-89$;
$59 \%(77 / 131)$ had spent more than 20 years in hospital compared to $21 \%(28 / 131)$ with a length of stay of less than 10 years; and $63 \%(82 / 131)$ had moderate levels of intellectual disability compared to $20 \%(26 / 131)$ with high levels of ability. Almost two-thirds of the entire group were discharged to private nursing homes (ie. typically large privately-owned settings of 20 places or more). The remainder were relocated to private $(12 \%, 25 / 214)$ or voluntary sector $(10 \%, 22 / 214)$ residential homes and to public (ie. DHSS owned) hostels or group homes (13\%, $28 / 214$ ). Only five people (2\%) returned home to their families. Ninety-one per cent (196/214) were still living in the community after 12 months while six per cent (14/214) had been re-admitted to hospital owing mainly to behavioural problems such as aggression. Four people $(2 \%)$ had died - two from pneumonia and two from cancer.

\section{Use of core services}

The five services most commonly used by the 197 people for whom information was available included general practitioners (GP), chiropodists, social workers, dentists and consultant (learning disability) psychiatrists respectively (Table 1). Two-thirds (95/144) of those who had seen a GP had up to three contacts in the six-month period, $41 \%$ of which were domiciliary (home) visits. Twenty per cent fewer private nursing home residents than in voluntary or public settings had seen a GP (Table 1). Sixty-three per cent (124/197) of people had seen a chiropodist during the previous six months, most of whom were public sector residents. Those living with their families had no contact with chiropody services.

Social workers were the third most commonly used service $(60 \%, 119 / 197)$ and were seen regularly (ie. at least once a month) by almost one quarter of people. All four people living with their families had also seen a social worker while the same was true for over $75 \%$ of public sector residents (Table 1). However, fewer people living in private nursing homes than elsewhere had received this service. Almost half (93/197) had also received dental care, $87 \%$ of whom had seen a dentist at least twice in the previous six months. Private residential home residents were 
least likely to have received this service. Almost 25\% (46/197) had seen a consultant psychiatrist during the previous six-months including $37 \%$ more people from settings run by the voluntary sector than private or public accommodation (Table 1).

\section{Staff-perceived availability and appropriateness of 'core'} services

Very few services were rated by care staff as unsatisfactory. Unmet need was indicated in only two cases - for chiropody and consultant care - while barriers to service provision (eg. 'poor review of client needs') were noted for three people who were seeing a social worker. Otherwise, all five services were rated as satisfactory.

\section{Other care staff inputs}

All 197 people had received one-to-one support (two hours per week, on average), two-thirds of whom $(130 / 197)$ had received more than eight hours a week. However, $40 \%$ (79/197) were judged to require more support of this kind particularly in areas related to social skills development. Ninety per cent had a designated keyworker and care review meetings had been organised for $78 \%(153 / 197)$ of people, most of which (122/153) had taken place bimonthly and had involved some form of care planning, service packaging, monitoring or reassessment $(73 \%, 112 / 153)$. At least one professional (usually a social worker) had attended $73 \%$ of meetings, two had been present in almost half and three had attended $29 \%$ of meetings. Social workers, psychiatrists and GPs were most likely to be involved in care reviews.

The majority of people had not used hospital services during the previous six months. For example, six people $(3 \%)$ had been re-admitted briefly to a learning disability hospital. However, a quarter of the group had visited a general hospital, $15 \%$ (30/197) of whom had attended an outpatient clinic and 9\% (17/197) of whom had received general hospital inpatient care.

Day services, work and daytime activities

Almost half of the group were attending clubs while $27 \%$ were visiting a day centre on a regular basis (see Table 3). However, participation in open or sheltered employment settings was very limited. Furthermore, $81 \%(51 / 63)$ of those involved in 'work' were participating in work activities available in social education or adult training centres. While structured and work-related day care activities were all provided off-site, sizeable proportions of people were involved in other daytime and recreational activities such as shopping and outings which tend to be organised on a group-basis (Table 3). Furthermore, $43 \%(85 / 197)$ of people had visited friends/relatives on at least one occasion during the previous six months.

\section{Service 'packages'}

Former patients had received an average of five services. Thirty-seven per cent (73/197) had received three or fewer services while the same proportion had been in contact with six or more different services. It was difficult to determine broad trends by sector owing to the predominance of private sector accommodation. Nonetheless, $47 \%$ $(58 / 122)$ of private nursing home residents had received fewer than four services compared to only $29 \%$ of those in private residential (6/21) and public sector accommodation $(8 / 28)$ and $14 \%(3 / 22)$ in voluntary settings. A

Table 2: Other care staff inputs

\begin{tabular}{lcc}
\hline Care staff input (for previous 6 months) & $\begin{array}{c}\text { No. of people } \\
(\mathbf{n}=197)\end{array}$ & $\%$ \\
In receipt of direct one-to-one support & 197 & 100 \\
In need of more one-to-one support & 79 & 40 \\
Had a nominated keyworker & 179 & 90 \\
CPN/Staff Nurse & 63 & 35 \\
Nursing/Care Assistant & 97 & 54 \\
Social Worker/Project Worker & 2 & 1 \\
Direct meetings with keyworker & 66 & 37
\end{tabular}

which took place at least once a week

Care review meetings arranged for client

153

78

"Most were in need of social skills training or diversional therapy and neoded no more than seven additional hours of individual support.

**The keyworkers for a small proportion of residents were residential workers and officers-in-charge or accommodation managers.

Table 3: Daytime, work and social activities

Type of activity during previous 6 months No. of people $\quad \%$ $(n=197)$

\section{Day Centres}

Total attending

Mental health resource centre

Social education centre (SEC)

Generic day centre

Type not known

At least one weekly visit

0

5

1

37

政

.

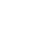


in the UK (eg. The All Wales Strategy $\left.{ }^{10}\right)$. The provision of day services and work activities, in particular, is important for the successful adaptation to community living for people with learning disabilities. According to our keyworkers, there may be some unmet need for structured day care and work activities despite the large proportion of people involved in daytime activities. The ways in which day care resources are used is critical to the process of normalisation'. However, at the time of this study (1993) service providers did not appear to be moving away from the conventional ways of organising and delivering services. These findings are similar to a number of English studies ${ }^{11.13}$ in which access to day care, meaningful occupation and employment were identified as areas of concern for former hospital residents with learning disabilities.

The people in our study were similar to those in the English Care in the Community Demonstration Programme ${ }^{14}$ on which the current study was modelled. GPs, as in the English study, played a central role in providing routine medical care. The consultation rate is approximately twice the UK average of 3.8 per annum. Over $75 \%(54 / 197)$ were also receiving regular medication mainly for physical illnesses and this may explain, in part, the high level of GP contact. However, it is equally plausible that keyworkers and GPs were responding in a proactive way towards this client group in the first year after discharge. Future work should examine why so many former hospital residents need to see a GP and whether or not GPs require support in order to provide appropriate care. The findings also raise questions about the adequate resourcing and support of future possibly more dependent cohorts of hospital leavers

Unfortunately, no information was available from this study on those who had died $(2 \%)$ or been re-admitted to hospital $(6 \%)$. It is possible that small numbers of people may have experienced translocation shock after discharge leading to a deterioration in their physical health or overall behaviour. For example, research has shown that discharge from hospital may have negative consequences in the short-term for a minority of vulnerable people. ${ }^{2}$

The input from social workers in this study was greater than in the Care in the Community Demonstration Programme. ${ }^{14}$ Proportionately more people in public provision had seen a social worker reflecting the routine delivery of social services in Northern Ireland to public sector residents. The frequent contact with social workers, GPs and chiropodists suggests that a reasonably high level of care was sustained beyond the critical first six months after discharge. Chiropody and dental services tended to be provided to groups of residents in the same home but while this institutionalised 'en-bloc' delivery ${ }^{15}$ may be a practical care arrangement, it might also be counterproductive in terms of achieving the goals of normalisation or in leading to over-provision. Both services were also commonly used in the study by Knapp et $\mathrm{al}^{14}$ although about $20 \%$ more people in our study $(63 \%)$ - most of whom had generally poor self-care skills - had seen a chiropodist.

The typically high level of staffing in private nursing homes may account for the relatively low use of community mental handicap nurses (CMHNs) (see Table 1), although only $36 \%$ of staff in nursing homes in Northern Ireland are qualified. ${ }^{16}$ In addition, many people with learning disabilities are now receiving care in a system dominated by professionals who also provide care to other client groups. ${ }^{17}$ However, the limited role of physiotherapists, occupational therapists (OT) and speech therapists (see Table 1) may be a cause for concern as these services can often be crucial in developing 'ordinary life' skills. ${ }^{18}$

There was some variation in service utilisation by type of accommodation despite the predominance of private sector homes. Patterns of service utilisation were dominated by services most likely to be used by the care settings to which people were discharged. For example, voluntary sector residents were most likely to be in contact with CMHNs and community-based consultants. They were also more likely to be receiving a larger number of services than people living elsewhere, most probably because of a lower level of professional staffing. On the whole, private sector residents were least likely to be 'high' service users. This may be due to the generally higher staffing levels or it may reflect an inappropriately low level of contact between privately run settings and public service providers. However, it is not clear to what extent these patterns reflect individual ability or better service delivery for public or voluntary sector residents. Furthermore, research has shown that there need not be a link between higher staffing levels and staff-resident interaction or resident participation in daily living activities. In addition, the unique integrated health and social services structure in Northern Ireland tends to facilitate the routine delivery of services to people under public sector care.

Staff-perceived quality and appropriateness of services were rated as satisfactory while unmet need for care was rarely indicated. This suggests that an adequate range of services was perceived to be available and that everyone had received regular one-to-one support. While these data are based on information provided by keyworkers rather than on detailed assessments, the professionals had a detailed knowledge of the services received by the residents to whom they were assigned and also had access to their personal records. This information is validated, in part, by findings from a survey of users' views in the larger evaluation ${ }^{7}$ which - though not directly related to service use indicated that people were more satisfied with life in the community than in hospital. While the needs of some people particularly in areas related to integration were not being fully met, information on care review and keyworker arrangements suggests a reasonable degree of service coordination and frequent, proactive professional involvement.

The development of a mixed economy of care for people with learning disabilities in Northern Ireland - in contrast to elsewhere in the $\mathrm{UK}^{17}$ - was limited in that most of the accommodation comprised large highly staffed private sector homes in which contact with the community was minimal. Furthermore, the findings from the larger evaluation showed that $27 \%$ of people were living in 'institutional' settings and that there were few dramatic changes in level of functioning or quality of life for the group as a whole. Arguably, therefore, few of these people would appear to have made a significant 'transitional step' in their lives. This raises the possibility that some people were subject to a process of transinstitutionalisation. Evidence from the UK ${ }^{20}$ suggests that community settings which provide richer and more intensive ranges of care packages tend to produce better outcomes. Therefore, it is possible that improvements in care packages for Northern Ireland residents could lead to greater outcomes particularly for people in private sector facilities. 
However, it is also important to note that the financial arrangements underlying private residential or nursing home care before the implementation of the community care reforms in 1993 may have prevented access to community-based services and, to some extent, the development of alternative types of accommodation. ${ }^{9}$ Substantial sums of money ( $£ 65$ million during 1993 1995) have since been transferred from the social security budget to the health and social services in order to help them meet their new responsibilities in terms of assessing and responding to community care needs. However, the guarantee that people already in (mainly private sector) places funded by the Social Security Agency have preserved rights to that funding so long as they remain in that accommodation created a new set of perverse incentives against needs-led care. Therefore, people whose needs for care change over time may be unable to move to alternative accommodation because the HSSBs are reluctant or unable to incur the costs of their care.

\section{Conclusion}

The shift from long-stay hospital to community-based care is one of the most significant changes in policy affecting people with learning disabilities. It also has important organisational, staffing and resource implications for health and social services. The majority of former hospital residents in Northern Ireland continue to have only a limited choice of mainly 24 hour nursing home accommodation which, in turn, influences the configuration of services which they receive following discharge from hospital. Our study was descriptive in nature and it is impossible, therefore, - without any standards against which to compare the findings (other than comparisons with the English study) - to determine how much service should be received. Furthermore, Northern Ireland already has two-and-a-half to three times more nursing home places than England, Scotland or Wales. It is possible, therefore, that without alternative types of provision, the more dependent people currently still in hospital may not be discharged to appropriate accommodation; this, despite the DHSS commitment to "reduce to zero by 2002 the number of long-stay patients in hospital". The opportunity to exercise choice over where to live is fundamental to the empowerment of service-users. ${ }^{3}$ Therefore, the provision of a range of appropriate accommodation and service packages is important in ensuring that people do not experience transinstitutionalisation, but are given adequate opportunity and support to develop greater self-reliance and autonomy which, in turn, will allow them to better manage their behavioural problems and expand their social networks.

Although the findings of this study are based on a 19901992 data set, they are of considerable relevance to current policy and clinical practice because of the very slow pace at which community care for people with learning disabilities in Northern Ireland has developed when compared to elsewhere in the UK. For example, the largest of the three mental handicap hospitals currently provides care for 375 people compared to 459 in 1994 representing a reduction of only $18 \%$ over the last five years. Whilst significant organisational change has taken place since this research was carried out, it is important to note that less than 10 per cent of people with learning disability are 'care managed'; the lion's share (almost $80 \%$ ) of care managed cases are older people.
Although it was not possible to determine to what extent service receipt was related to dependency, the type of community facility and, to some extent, the organisational factors currently involved in service delivery in Northern Ireland would appear to influence access to, and use of services. These findings reinforce the need for further research on the effectiveness and coordination of service delivery for former hospital residents with learning disabilities. Service planners and providers also need to be aware that the pattern of service provision, particularly in an evolving mixed economy of care, is likely to be very different for the more dependent cohorts of people who leave hospital in the future. However, improving or at least maintaining the quality of life and welfare of people with learning disabilities in Northern Ireland continues to be paramount in the policy of relocating care to the community.

\section{Acknowledgements}

This study was funded by the DHSS (Northern Ireland) and carried out as part of a larger evaluation on the costs and effectiveness of community care in collaboration with the Personal Social Services Research Unit at the University of Kent at Canterbury, England.

References

1. Emerson E, Hatton C. Moving out: relocation from hospital to community. London: HMSO, 1994.

2. Booth T, Simons K, Booth W. Outward Bound. Relocation and community care for people with learning difficulties. Milton Keynes: Open University Press 1990.

3. Salovuta T. Immediate psychological effects of deinstitutionalisation. In: Mansell J, Ericsson K (eds.) Deinstitutionalisation and community living. London: Chapman and Hall, 1996.

4. Department of Health and Social Services (DHSS (Northern Ireland)). A Regional Strategy for the Northern Ireland Health and Personal Social Services, 1987-1992. Belfast: DHSS (Northern Ireland), 1986.

5. Department of Health and Social Services (DHSS(Northern Ireland)). A Regional Strategy for the Northern Ireland Health and Personal Social Services, 1992-1997. Belfast: DHSS (Northern Ireland), 1991.

6. Department of Health and Social Services (DHSS(Northern Ireland)). A Regional Strategy for the Northern Ireland Health and Personal Social Services, 1997-2002. Belfast: DHSS (Northern Ireland), 1995.

7. Donnelly M, McGilloway S, Mays N et al. Opening New Doors. An evaluation of community care for people discharged from psychiatric and mental handicap hospitals. Belfast: HMSO, 1994.

8. Beecham J, Knapp MRI. Costing psychiatric interventions. In: Thornicroft G, Brewin C, Knapp MRJ (eds). Measuring mental health needs. London: Gaskill, 1992.

9. Beecham J, Knapp M, McGilloway S et al. The cost-effectiveness of community care for adults with learning disabilities. J Intellect Disability Res 1997; 41: 30-41.

10. The Welsh Office. All Wales Strategy for the development of services for mentally impaired people. Wales: The Welsh Office, 1983.

11. Korman N, Glennerster $\mathrm{H}$. Closing a hospital: a political and economic study. Milton Keynes: Open University Press, 1990.

12. Bond S, Smith M, Pitcairn K. Community resettlement from hospital of people with a mental handicap. Centre for Health Services Research, Report No.53. Newcastle: Centre for Health Services Research, University of Newcastle-upon-Tyne, 1992.

13. Cambridge P, Hayes L, Knapp MRJ, Fenyo A, Gould E. Care in the community five years on. Aldershot: Ashgate, 1994.

14. Knapp MRJ, Cambridge P, Thomason C, Beecham J, Allen C, Darton R Care in the community: challenge and demonstration. Aldershot: Ashgate/PSSRU, 1992

15. Goffman E. Asylums: Essays on the social situation of mental patients and other inmates. New York: Anchor Books, Doubleday, 1961.

16. Registration and Inspection Unit Sixth Annual Report Belfast: Eastern Health and Social Services Board, 1997.

17. Mansell J. Staffing and staff performance in services for people with severe or profound learning disability and serious challenging behaviour. J Intellect Disability Res 1995; 39: 3-14.

18. House of Commons Select Committee on Social Services. Community care, HPC13-I, Session 1984-85. London: HMSO, 1985.

19. Felce D. Quality of support for ordinary living. In: Mansell J, Ericsson K (eds). Deinstitutionalisation and community living. London: Chapman and Hall, 1996.

20. Emerson E, Hatton C. Residential provision for people with learning disabilities: An analysis of the 1991 census. University of Manchester: Hester Adrian Research Centre, 1996.

21. Department of Health and Social Services (DHSS (Northern Ireland)). Review of policy for people with a learning disability. Belfast: DHSS (Northern Ireland), 1994. 


\section{Depression}

\section{Breakthrough}
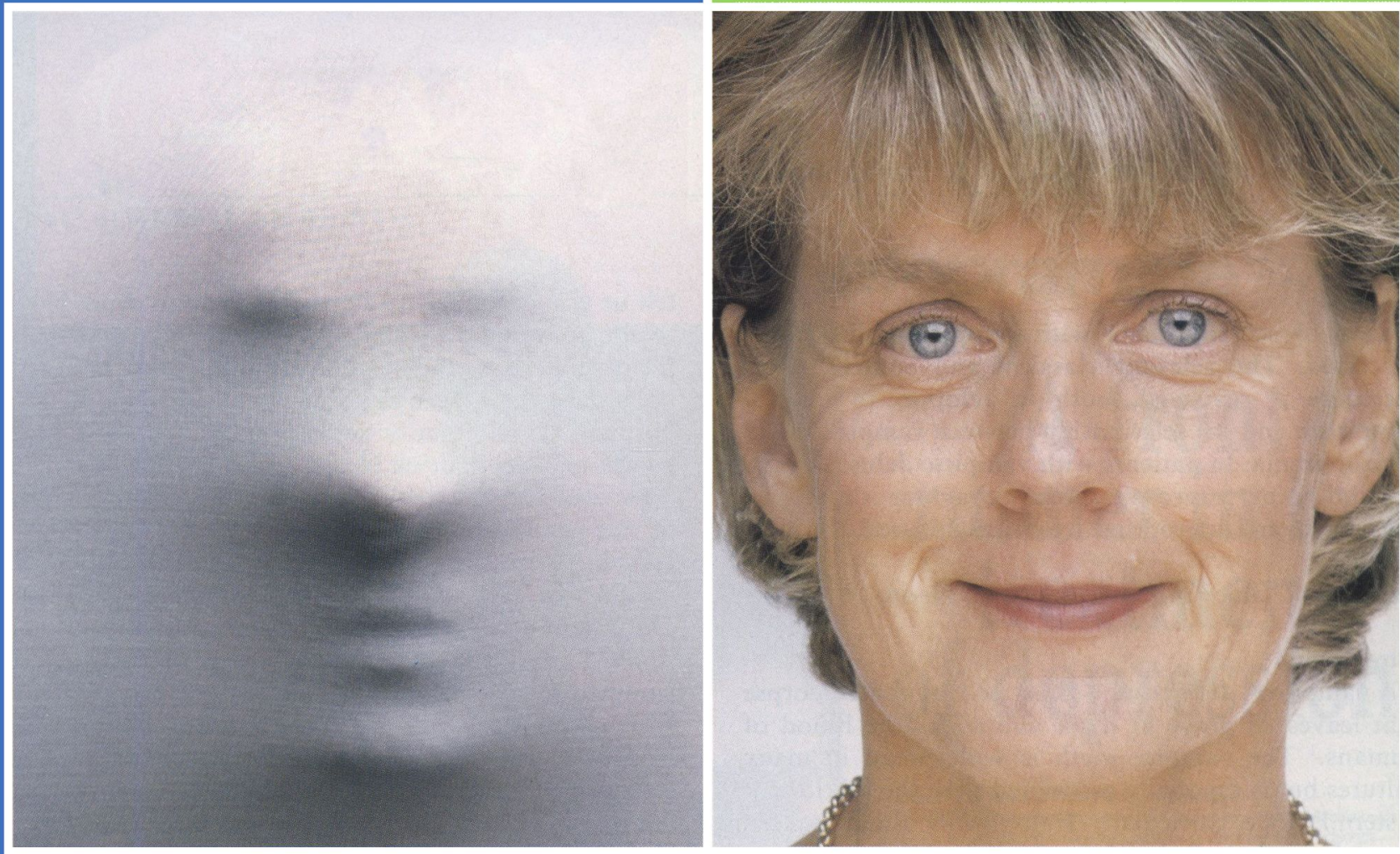

\section{A totally new treatment for people facing depression}

Edronax is a selective Noradrenaline Reuptake Inhibitor (selective NRI), a new generation of antidepressant, with proven efficacy in all grades of depression with or without associated anxiety.'

Well tolerated, this new treatment is also 'particularly useful in the elevation of patients' motivation, energy and drive'.?

\section{NEW}

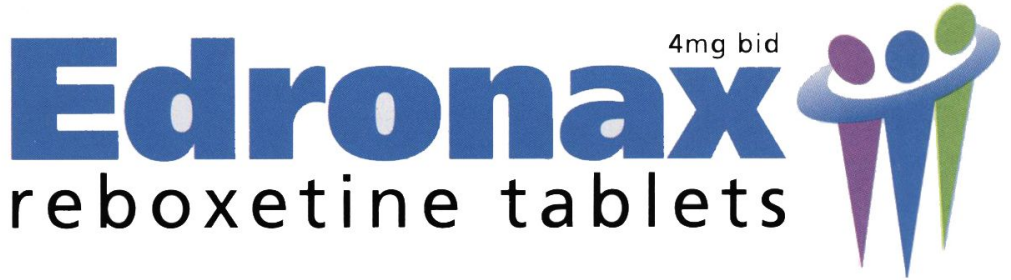

\section{Released from depression Reunited with the world}

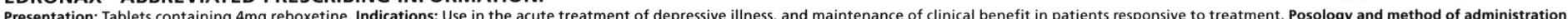

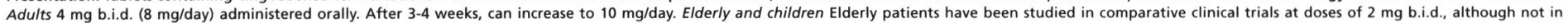

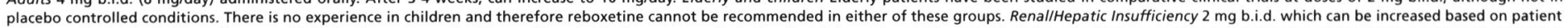

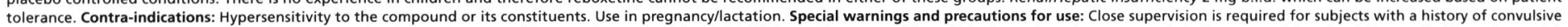

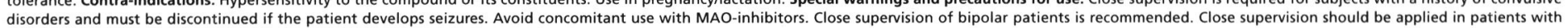

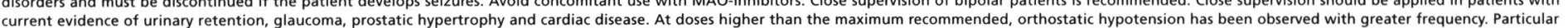

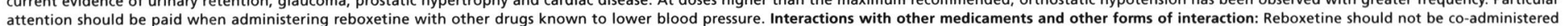

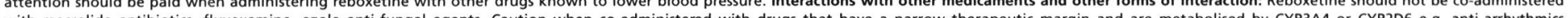

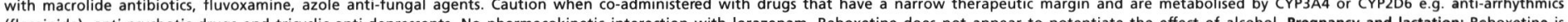

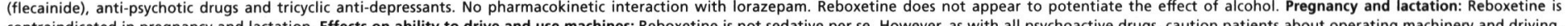

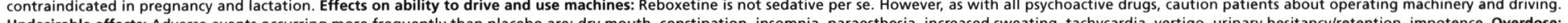

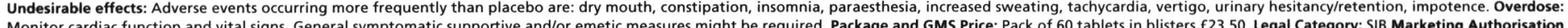

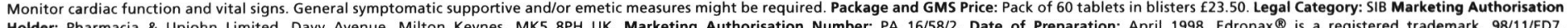

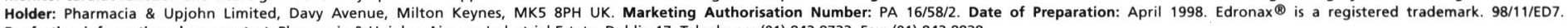
For further information please contact: Pharmacia \& Upjohn, Airways Industrial Estate, Dublin 17. Telephone: (01) 8428733 . Fax: (01) 8428828. 